\title{
KAJIAN KONSEP ARSITEKTUR HIJAU PADA BANGUNAN BEITOU PUBLIC LIBRARY
}

\author{
Aditya Fhazar Nugraha1*, Yeptadian Sari ${ }^{2}$ \\ Program Studi Arsitektur Fakultas Teknik Universitas Muhammadiyah Jakarta ${ }^{1 *}$, \\ Program Studi Arsitektur Fakultas Teknik Universitas Muhammadiyah Jakarta ${ }^{2}$ \\ e-mail: ${ }^{* 12016460002 @ f t u m j . a c . i d, ~}{ }^{2}$ Yeptadian.sari@gmail.com
}

\begin{abstract}
Abstrak_ Bangunan perpustakan memiliki manfaat dimana terdapat ilmu pengetahuan yang bisa dimanfaatkan dengan baik, namun ketertarikan untuk menggunakan perpustakaan tersebut perlu kualitas pelayanan dan tersedianya buku yang lengkap sehingga dapat menarik lebih banyak pengguna untuk mengunjungi perpustakaan. Peranan prinsip rancangan bangunan arsitektur hijau lebih efisien digunakan pada bangunan perpustakaan karena prinsip ini sangat membantu bangunan dalam menciptakan ruang yang nyaman sehingga pengunjung yang datang merasa nyaman berada didalam bangunan. Tujuan mengkaji konsep arsitektur hijau pada bangunan perpustakaan ini untuk mengetahui apa saja konsep arsitektur hijau yang diterapkan pada bangunan. Metode yang digunakan untuk menganalisis yaitu metode deskriptif yang mana menggambarkan bangunan berdasarkan data yang ada. Prinsip yang digunakan untuk menganalisis penerapan arsitektur hijau pada bangunan Beitou Public Library yaitu penempatan lokasi dan tapak, pengolahan tapak, penghematan energi, pemanfaatan energi terbarukan, konsep zero energi building, dan material bangunan. Penerapan yang digunakan pada bangunan Beitou Public Library berdasarkan prinsip yang digunakan, secara keseluruhan terdapat 1 prinsip yang tidak diterapkan bangunan ini yaitu penerapan konsep zero energi building karena Beitou Public Library masih memanfaatkan energi buatan seperti penggunaan penghawaan buatan, sedangkan konsep zero energi building itu sendiri tidak memanfaatkan penghawaan buatan.
\end{abstract}

Kata kunci : Perpustakaan; Bangunan; Arsitektur Hijau; Konsep; Ilmu Pengetahuan,

\begin{abstract}
Library building has benefits where there is knowledge that can be put to good use, but the interest in using the library needs quality service and the availability of complete books so that it can attract more users to visit the library. The role of green architecture building design principles is more efficiently used in library buildings because this principle greatly helps the building in creating a comfortable space so that visitors who come feel comfortable inside the building. The purpose of studying the concept of green architecture in this library building is to find out what green architecture concepts are applied to the building. The method used to analyze is descriptive method which describes the building based on existing data. The principles used to analyze the application of green architecture in Beitou Public Library buildings are location and site placement, site processing, energi savings, renewable energi utilization, zero energi building concepts, and building materials. The application used in the Beitou Public Library building is based on the principles used, overall there is one principle that is not applied to this building, namely the application of the zero energi building concept because the Beitou Public Library still utilizes artificial energi such as the use of artificial ventilation, while the concept of zero energi building itself is not making use of artificial ventilation.
\end{abstract}

Keywords : Library; Building; Green Architecture; Concept; Science.

${ }_{1}^{1}$ Program Studi Arsitektur Fakultas Teknik Universitas Muhammadiyah Jakarta 2 Program Studi Arsitektur Fakultas Teknik Universitas Muhammadiyah Jakarta 


\section{PENDAHULUAN}

Perpustakaan memiliki peran baik dalam menaikan kegemaran membaca maupun meningkatkan pengetahuan. Dalam hal ini perpustakaan memberikan keikutsertaan dalam menaikan minat baca di Indonesia seperti tempat penyimpanan buku, sejarah dan lain sebagainya. Adanya perpustakaan ini bukan hanya sebatas tempat penyimpanan dan peminjaman buku saja tetapi untuk menyediakan bacaan dengan layanan yang baik. Namun tergantung bagaimana fasilitas dan ketersediaan buku yang ada (Abdul, 2016).

Perencaanan arsitektur, struktur, utilitas, dari segi teknis ada kenyamanan, keamanan, dan kesehatan selalu berkaitan dengan masalah yang ada pada bangunan. Dalam perwujudannya pemerintah telah menerbitkan UU Bangunan Gedung No.28 Tahun 2002. Lingkungan sekitar sangat berpengaruh terhadap aman dan nyamannya bangunan itu sendiri. Tergantung bagaimana objek yang ada untuk menerapkan aman dan nyaman terhadap bangunan. Bangunan yang ingin menerapkan atau menjadikan bangunan aman dan nyaman maka syarat yang ada harus digunakan. Menerapkan ini juga lebih baik dihubungkan dengan kualitas hemat energi dari bangunan endangsih, 2002 dalam (Anisa, 2010).

Pada era sekarang yang namanya pembangunan sangat dibutuhkan sehingga sangat berkaitan dengan kondisi tapak dan sumber daya energi yang dibutuhkan untuk pembangunan tersebut. Munculnya konsep arsitektur hijau sebagai bentuk untuk dapat memanfaatkan tapak dan juga mengurangi penggunaan sumber daya alam seperti sustainable (berkelanjutan), earthfriendly (ramah lingkungan), dan high performance building (bangunan dengan performa sangat baik) yang mana dapat membantu bangunan dalam menjaga lingkungan sekitar. Faktor yang dapat menentukan ukuran arsitektur hijau berdasarkan pada kepedulian untuk menjadikan lingkungan lebih hijau . (Sudarwani, 2012).

Adapun penjelasan mengenai prinsip dasar arsitektur hijau menurut Brenda dan Robert Vale (1991) dalam (Afifah et al., 2018) yaitu:

a. Conserving energi, memanfaatkan energi alami dari alam sekitar dan mengurangi penggunaan pencahayaan buatan dan penghawaan buatan.

b. Working with climate. Menyesuaikan keadaan sekitar pada saat mendesain bangunan.

c. Minimizing new resources, tidak terlalu banyak menggunakan sumber daya alam agar dapat digunakan di masa mendatang.

d. Respect for site, mengikuti keadaan atau kondisi tapak pada saat mendesain sehingga tidak merusak lingkungan sekita.

e. Respect for site, memikirkan semua kebutuhan yang dibutuhkan oleh semua pengguna.

Menurut (Karyono, 2014) Rancangan arsitektur hijau yang baik ialah yang menerapkan system hemat energi yang membuat lingkungan sekitar menjadi lebih baik. Untuk bisa mendapatkannya maka area sekitar harus memenuhi kriteria rancangan arsitektur hijau. Adapun elemen-elemen yang harus dipenuhi sehingga mencapai kriterianya.

a. Lokasi dan Tapak

Penempatan area tapak harus jauh dari bahaya yang bisa mengancam pengguna.

b. Pengolahan tapak dan peningkatan kualitas tapak

Pada saat merancang bangunan disarankan tidak terlalu megubah area tapak karena dapat mengganggu kualitas tanah. 
c. Penghematan energi

Hemat energi yang dimaksud ialah mampu membuat bangunan meminimalkan penggunaan energi buatan, dan membuat bangunan memanfaatkan sumber daya alam sekitarnya.

1) Meminimalkan radiasi matahari secara langsung

2) Menghindari arah hadap bangunan ke matahari langsung.

3) Memaksimalkan sirkulasi udara pada bangunan.

4) Memanfaatkan sinar matahari yang tidak terkena kebangunan sebagai penerangan. .

5) Penggunaan warna dan tekstur luar bangunan.

6) Desain luar bangunan.

d. Pemanfaatan energi terbarukan

Energi terbarukan ini sangat ramah terhadap lingkungan yang mana penggunaannya bisa secara terus menerus sehingga membantu mengemisi co2 dan efek gas rumah kaca.. Adapun energi terbarukan tersebut antara lain energi surya, energi angin, energi air, energi panas bumi.

1) Energi surya

Solar sel (photovoltaic) Teknologi yang sering digunakan untuk mendapatkan listrik dari sinar matahari.

2) Energi angin

Pembangkit listrik tenaga angin (wind-power), Teknologi yang memerlukan angin yang besar agar dapat merasakan manfaatnya.

3) Energi air

Pembangkit lsitrik tenaga air (hydro-power)

Teknologi ini juga banyak digunakan sebagai alternatif untuk menghasilkan energi listrik.

- Energi panas bumi

Teknologi yang digunakan untuk membuat ruang menjadi panas, teknologi ini memanfaatkan panas dari perut bumi.

4) Konsep Zero Energi Building (ZEB)

Konsep yang memaksimalkan pemanfaatan energi alami.

5) Material bangunan

- Material terbarukan (Renewable Materials)

Material yang bisa digunakan secara berkelanjutan.

- Material bekas ( Reuse Materials)

Pemanfaatan material lama yang bisa digunakan untuk bangunan yang baru.

- Material daur ulang (Recycle Materials)

Memanfaatkan material lama sebagai material yang akan digunakn untuk fungsi yang lainnya.

- Material sehat tidak mengkontaminasi lingkungan

Penggunaan material yang tidak mengganggu pengguna seperti penggunaan cat yang berbau dan lain-lainnya.

Rumusan masalah dalam penelitian ini, bahwa apa saja prinsip-prinsip bangunan berkonsep arsitektur hijau Beitou Public Library?. Bagaimana penerapan konsep arsitektur hijau pada bangunan perpustakaan Beitou Public Library? Tujuan dari penelitaian ini diharapkan kita dapat memahami bagaimana penerapan konsep arsitektur hijau pada bangunan perpustakaan dan apa saja prinsip-prinsip bangunan berkonsep arsitektur hijau. 


\section{METODE}

Metode penelitian yang digunakan dalam penelitian deskriptif kualitatif. Metode pengumpulan data dilakukan dengan survey primer berupa observasi, wawancara, studi pustaka, dan dokumentasi. Metode observasi dilakukan untuk mengetahui penerapan pendekatan arsitektur hijau pada bangunan perpustakaan. Metode wawancara dilakukan untuk memenuhi respon para pengguna dan pengunjung pada bangunan perpustakaan. Cara pengambilan data pada penelitian ini adalah dengan membandingkan penerapan pendekatan arsitektur hijau pada beberapa bangunan perpustakaan yang ada. Penelitian pendekatan gaya arsitektur hijau pada bangunan perpustakaan universitas multimedia nusantara.

Gambar dibawah ini merupakan gambar Beitou Public Library beada di lokasi taman Beitou di area mata air panas Beitou, sekitar $15 \mathrm{~km}$ di utara Kota Taipei yang mana berdasarkan peta lokasi bangunan ini berada di area yang cukup banyak lahan hijaunya.

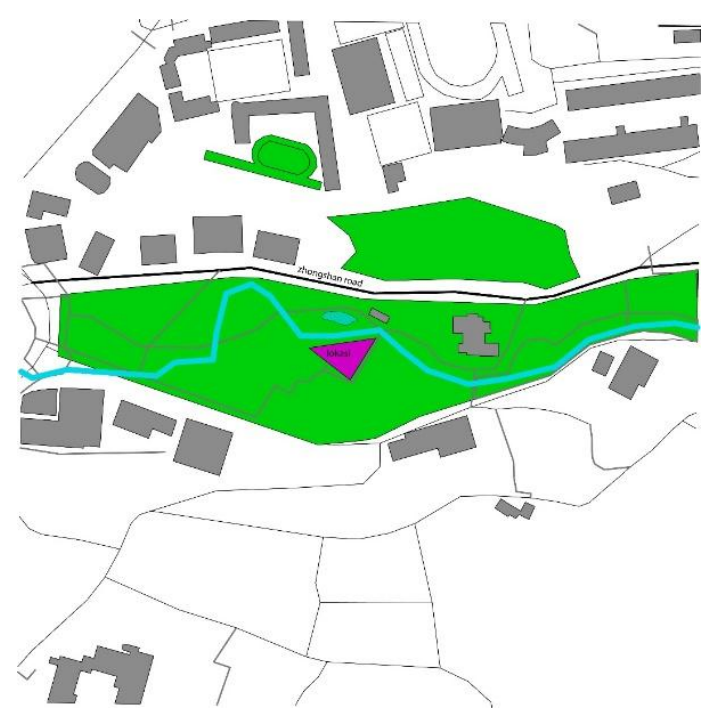

Gambar 1. Peta Beitou Public Library Sumber : Dokumentasi Pribadi, 2019

\section{HASIL DAN PEMBAHASAN}

Perpustakaan Beitou Public Library memiliki arsitektur dan sistem operasi yang menarik. Perpustakaan Beitou Public Library mendapat penghargaan sebagai salah satu gedung terindah yang ada di dunia. Perpustakaan ini menerapkan konsep arsitektur hijau. Beitou Public Library dilengkapi dengan aspek-aspek bangunan ramah lingkungan yang menjadikannya salah satu arsitektur Asia Timur yang paling hemat energi dan ramah lingkungan serta mendapatkan Green Building Label Diamond pada tahun 2010.

\section{A. Data Fisik Bangunan Beitou Public Library}

1. Deskripsi Bangunan

a. Nama Bangunan : Beitou Public Library

b. Jenis : Perpustakaan

c. Pendiri : Bio-Architecture Formosana

d. Lokasi : Taman Beitou di area mata air panas Beitou, sekitar $15 \mathrm{~km}$ di utara Taipei 
2. Eksterior dan Interior Bangunan Beitou Public Library

Perpustakaan Beitou berperan aktif dalam memperbaiki lingkungan dengan menjadi hemat energi dan air. Perpustakaan ini dibangun dengan menggunakan struktur kayu. Menggunakan bukaan cukup besar di setiap ruangan.

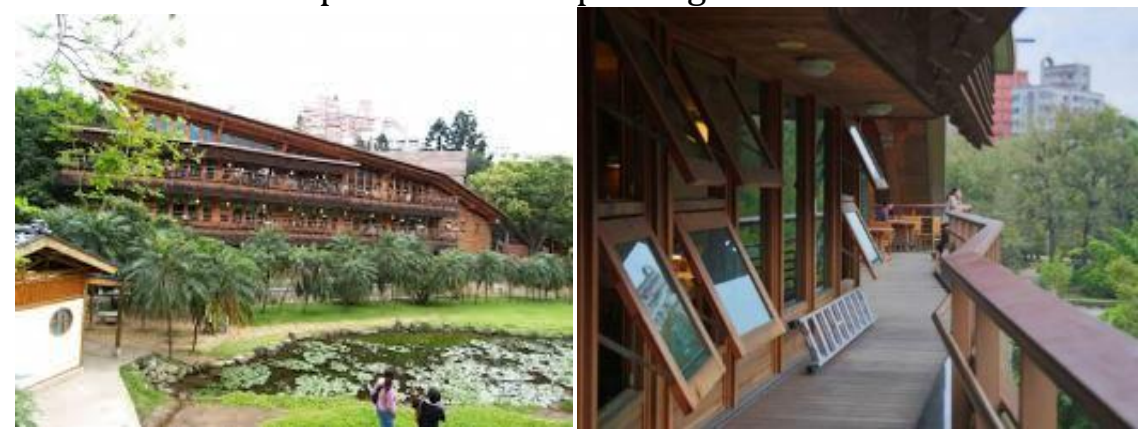

Gambar 2. Eksterior dan Bukan Beitou Public Library Sumber: Mak_Simplicity_of_Sustainability, 2019

Terdapat ruang dengan jendela besar yang dijadikan sebagai sumber cahaya bagi ruangan tersebut. Bangunan ini juga menghemat air dengan cara menampung air hujan yang nantinya akan dipakai untuk toilet. Sebagian atap perpustakaan ditutup menggunakan solar panel untuk mengubah cahaya matahari menjadi energi listrik
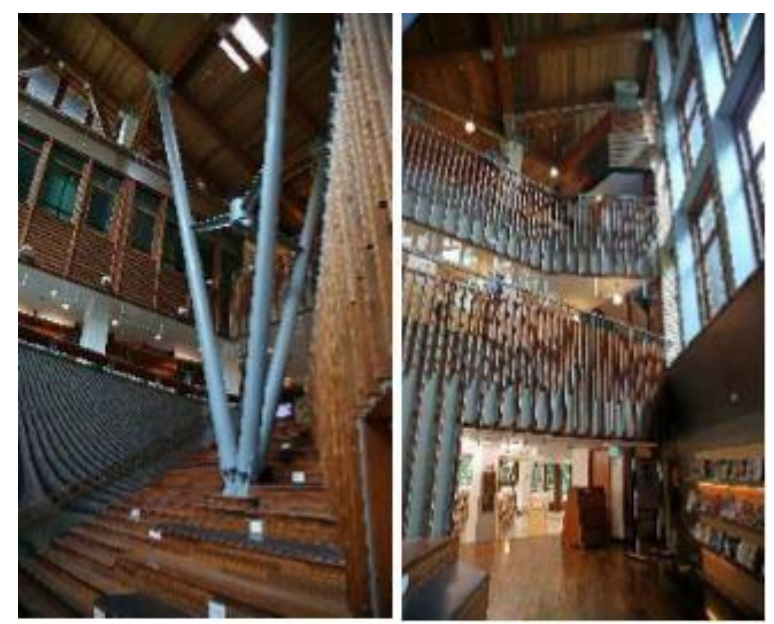

Gambar 3. Atrium Beitou Public Library

Sumber: Mak_Simplicity_of_Sustainability, 2019
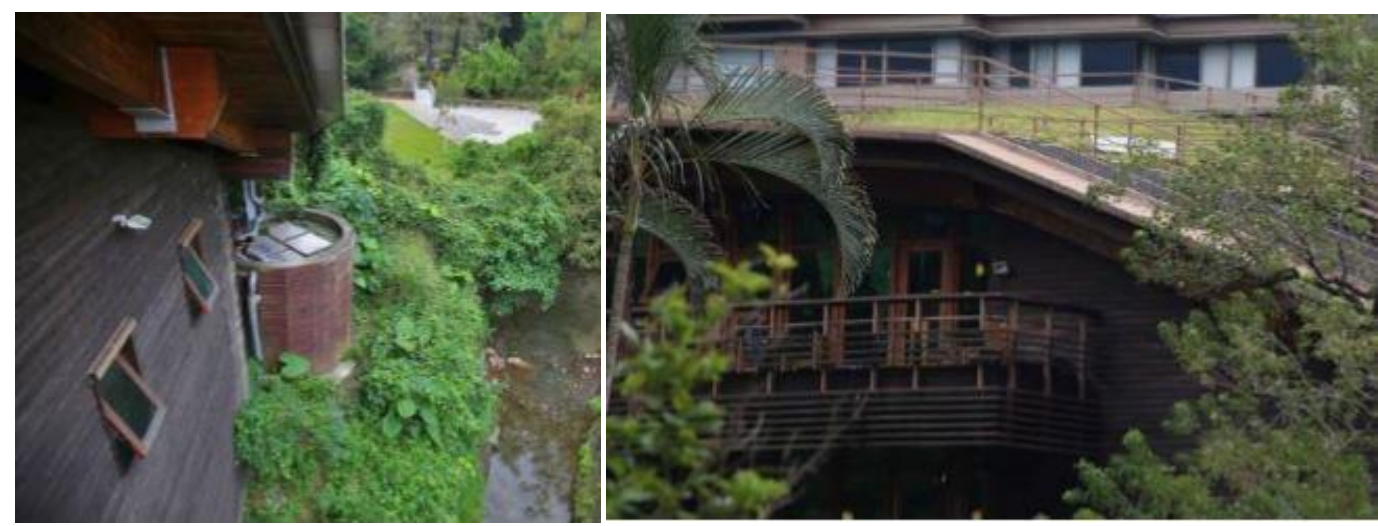

Gambar 4. Rain Water Storage And Roof Solar Panel Sumber : Mak_Simplicity_of_Sustainability, 2019 
Penghematan energi, memanfaatkan energi alami dari alam sekitar dan mengurangi penggunaan pencahayaan buatan dan penghawaan buatan. Pada tampak bangunan dibawah ini terlihat bahwasannya bangunan ini mengunakan bukaan yang cukup banyak dan juga material bangunan yang digunakan pada bangunan ini dapat membantu menghemat penggunaan energi buatan. Material kaca yang digunakan membantu bangunan untuk dapat memanfaatkan pencahayaan alami sehingga bangunan tidak perlu menggunakan pencahayaan buatan pada siang hari.

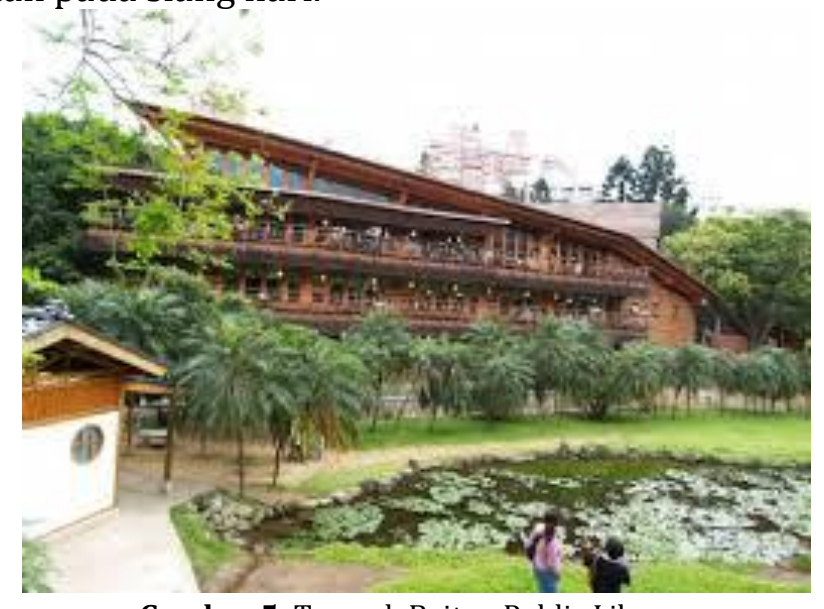

Gambar 5. Tampak Beitou Public Library

Sumber: Mak_Simplicity_of_Sustainability, 2019

Kajian Arsitektur Hijau pada bangunan perpustakaan ini terpaku pada prinsipprinsip arsitektur hijau menurut Karyono (2014). Berikut ini penjelasan mengenai prinsip arsitektur hijau berdasarkan teori yang digunakan untuk mengkaji bangunan Beitou Public Library.

Berdasarkan prinsip-prinsip arsitektur hijau menurut Karyono (2014), prinsip arsitektur hijau yang diterapkan pada bangunan Beitou Public Library adalah Pemilihan lokasi dan tapak bangunan sangat mempertimbangkan keadaan lingkungan sekitar yang mana lingkungan harus memiliki potensi yang baik untuk penggunanya dan juga menghindari bahaya bagi penggunanya. Gambar dibawah ini merupakan penjelasan prinsip yang diterapkan pada Beitou Public Library.

\section{B. Penempatan lokasi dan tapak}

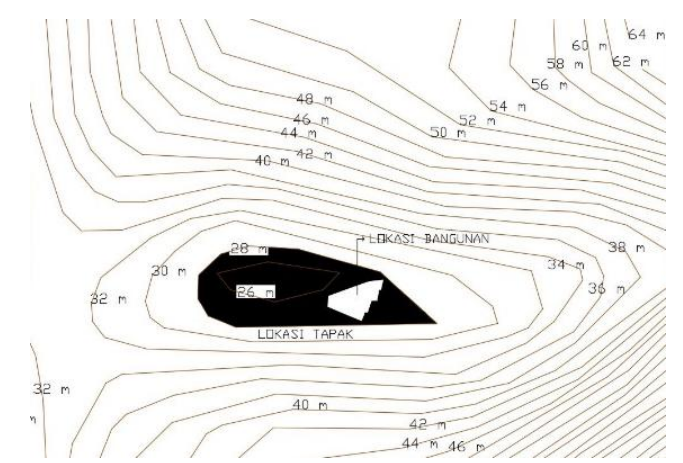

Gambar 6. Kontur Tanah Beitou Public Library Sumber : Google Earth App, 2020 
Terlihat pada gambar di atas bahwasannya lokasi dan tapak bangunan terletak pada kontur tanah yang paling rendah, dengan adanya air hujan yang mengalir ke titik yang paling rendah ketika hujan sehingga area lokasi dan tapak bangunan ini memiliki potensi banjir. Dengan adanya potensi banjir yang terjadi pada lokasi bangunan, rancangan pada Kawasan ini memiliki banyak sekali area hijau yang menjadi resapan air dan juga menggunakan aliran air sehingga dapat membantu menanggulangi banjir yang berpotensi terjadi pada lokasi bangunan ini. Dibawah ini merupakan gambar dimana area resapan air bangunan.

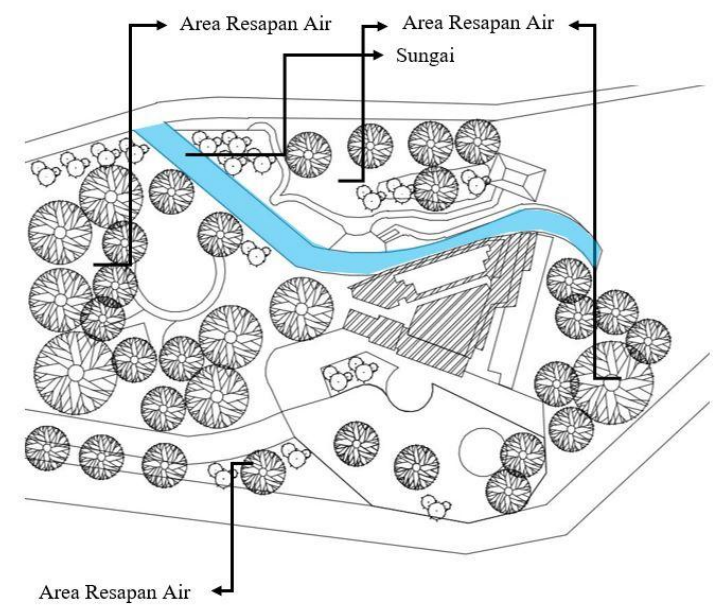

Gambar 7. Area Resapan Air Sumber : Dokumen Pribadi, 2020

1. Pengolahan Tapak

Pada tapak Beitou Public Library, Taipei, Taiwan ini terlihat bahwasannya perpustakaan ini memiliki tapak yang mengikuti jalan yang berada di depannya. Dalam hal pengolahan tapak bangunan ini menerapkan penghijauan disekitar bangunannya yang mana itu baik untuk lingkungan sekitar bangunan dan juga resapan air yang mana bagus untuk kualitas tanah. Gambar dibawah merupakan pengolahan tapak dari beitou public library.

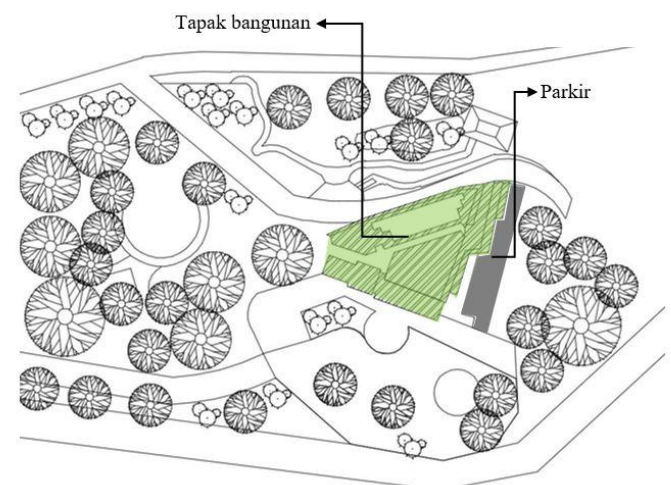

Gambar 8. Pengolahan Tapak Beitou Public Library Sumber : Dokumen Pribadi, 2020 
Pada perkerasannya juga terdapat penghijauan yang mana juga baik untuk pengunjung pejalan kaki yang datang sehingga bangunan ini sangat bisa dikunjungi pejalan kaki maupun pengunjung berkendara yang mana disediakan parkiran untuk penggunanya.

2. Penghematan Energi

Bangunan beitou public library ini berorientasi kearah utara yang mana bangunan ini menghindari radiasi matahari secara langsung sehingga panas yang diterima terhadap ruang didalamnya lebih sedikit sehingga membantu ruang untuk menjaga tetap terlihat lebih nyaman.

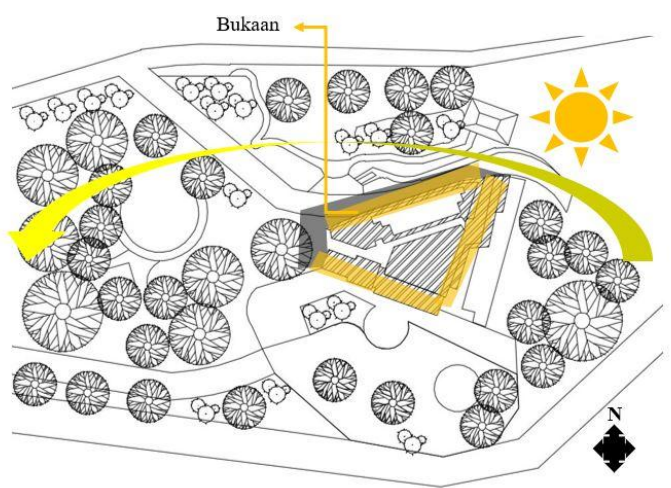

Gambar 9. Orientasi bangunan Sumber: Dokumen Pribadi, 2020

Memanfaatkan sinar matahari tidak langsung untuk pencahayaan ruang diterapkan pada bangunan ini dengan membuat bukaan pada sisi bangunan yang tidak terkena paparan sinar matahari secara langsung sehingga membuat ruang mendapatkan pencahayaan ruangan. Dalam hal ini penerapan bukaan pada tiap sisi bangunan merupakan langkah baik untuk membuat sirkulasi udara silang yang mampu membuat ruang menjadi lebih nyaman karena di iklim yang tropis bangunan dengan penggunaan bukaan seperti ini sangat dibutuhkan yang mana sangat bermanfaat bagi kualitas udara yang masuk selalu bertukar untuk menghindari udara yang kurang baik. Pada gambar 9 memperlihatkan bahwa bangunan ini menggunakan sirkulasi udara silang yang mana sangat efisien untuk digunakan pada bangunan yang berada di iklim tropis.

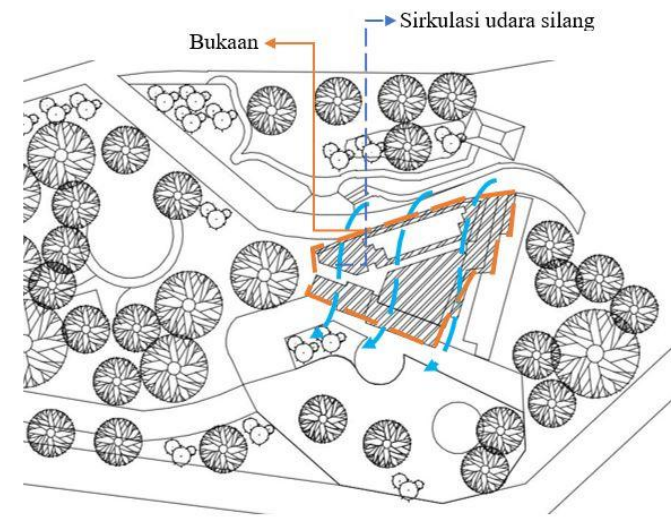

Gambar 10. Sirkulasi Udara Sumber : Dokumen Pribadi, 2019 
Pada bangunan beitou public library menerapkan system sirkulasi udara silang yang mana sangat baik untuk kualitas udara di dalam ruangan. Dalam hal ini juga dapat membantu bangunan untuk tidak menggunakan system penghawaan buatan yang mana mempengaruhi global warming. Ini merupakan salah satu langkah untuk menjaga bumi agar tetap bisa di nikmati alamnya di generasi yang akan datang. Dalam hal ini juga menggunakan bukaan yang banyak mampu memaksimalkan pelepasan panas didalam bangunan sehingga menjaga udara di dalam tetap nyaman.

3. Pemanfaatan Energi Terbarukan

Bangunan beitou public library yang mana memanfaatkan energi solar sel (photovoltaic) yang mana teknologi ini menghasilkan energi listrik yang dapat membantu bangunan untuk mengurangi penggunaan listrik berbayar dan juga membantu mengurangi pemanasan global juga mengemisi co2.

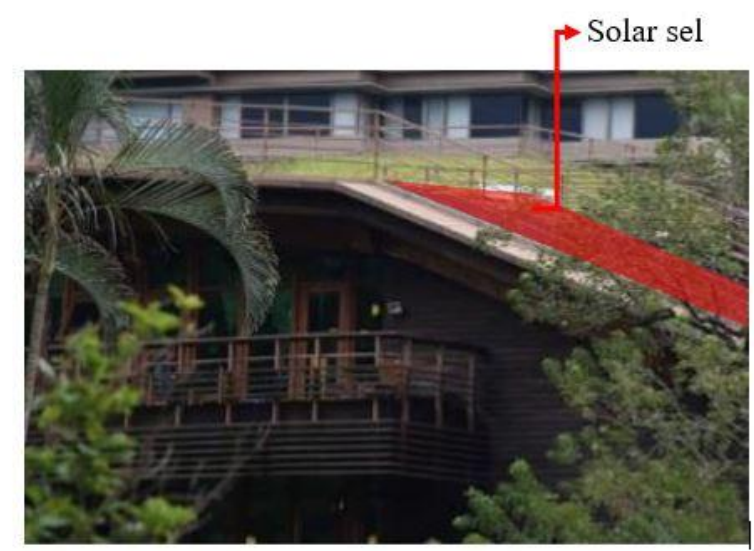

Gambar 11. Solar Sel

Sumber : http://cina.panduanwisata.id

4. Pengunaan Material Ramah Lingkungan

Pada tampak bangunan ini terlihat bahwasannya bangunan ini dominan menggunakan material kayu yang mana material ini merupakan salah satu material terbarukan Penggunaan material terbarukan (Renewable Materials) karena material ini dapat kita tanam untuk digunakan kembali sehingga material ini bisa digunakan secara berkelanjutan. Penerapan material terbarukan jenis kayu dan kaca pada perpustakaan ini membuat bangunan lebih berkesan alami dan hangat.

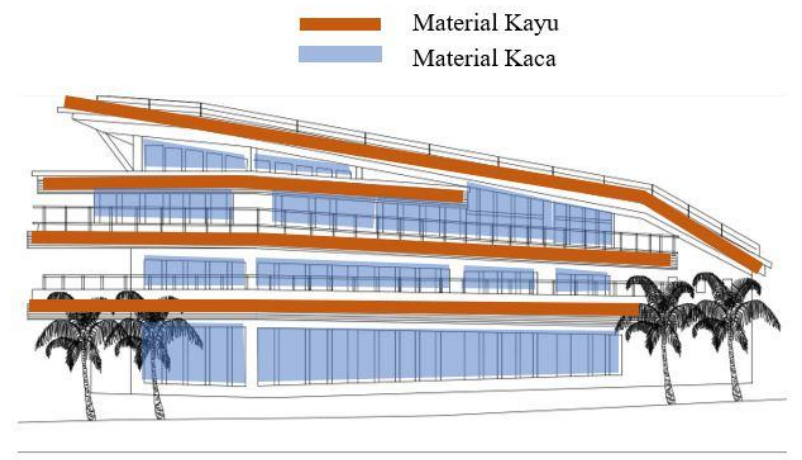

Gambar 12. Tampak Bangunan

Sumber : Dokumen Pribadi, 2019 
Pada bangunan perpustakaan ini tidak menerapkan penggunaan material bekas ( Reuse Materials) karena bangunan ini menggunakan material terbarukan yang dimana materialnya bisa bertahan lebih lama. Pada gambar tampak bangunan terlihat material yang diguanakan pada bangunan perpustakaan ini tidak menggunakan material daur ulang (Recycle Materials) karena bangunan ini banyak memanfaatkan material terbarukan yang dimana material ini bisa digunakan secara terus menerus. Perpustakaan beitou ini sama sekali tidak menggunakan cat karena bangunan ini menggunakan material kayu karena material ini memiliki warna natural yang terlihat menarik untuk ekstetika bangunan sehingga tidak perlu diberi warna. Selain itu juga bangunan ini menghindari penggunaan cat berbahan kimia karena memiliki bau yang dapat mengganggu pengguna perpustakaan tersebut.

Tabel 1. Penerapan Prinsip Arsitektur Hijau

\begin{tabular}{|c|c|c|}
\hline No. & Prinsip Arsitektur Hijau & Beitou Public Library \\
\hline 1. & Penempatan Lokasi dan Tapak & $\begin{array}{l}\text { Terletak pada kontur tanah yang cukup rendah sehingga berpotensi } \\
\text { terjadi banjir akan tetapi dengan memilki area hijau yang cukup luas } \\
\text { sehingga terdapat banyak area resapan air yang dapat membantu } \\
\text { mengurangi potensi terjadinya banjir. }\end{array}$ \\
\hline 2 & Pengolahan Tapak & $\begin{array}{l}\text { Berdasarkan kajian diatas bahwa perpustakaan ini tidak terlalu } \\
\text { banyak mengubah atau mengolah lahan sehingga kualitas lahan tetap } \\
\text { terjaga. }\end{array}$ \\
\hline 3. & Penghematan Energi & $\begin{array}{l}\text { Bangunan perpustakaan ini mengarah ke utara sehingga terhindar } \\
\text { dari panas sinar matahari secara langsung terhadap bangunan dan } \\
\text { memanfaatkan sinar matahari tidak langsung untuk pencahayaan } \\
\text { pada ruang serta memanfaatkan sirkulasi udara silang dengan } \\
\text { menggunakan bukaan di kedua sisi bangunan. }\end{array}$ \\
\hline 4. & Penggunaan Energi Terbarukan & $\begin{array}{l}\text { Beitou Public Library memanfaatkan energi solar sel (photovoltaic) } \\
\text { yang mana teknologi ini menghasilkan energi listrik yang dapat } \\
\text { membantu bangunan untuk mengurangi penggunaan listrik berbayar } \\
\text { dan juga membantu mengurangi pemanasan global juga mengemisi } \\
\text { co2. }\end{array}$ \\
\hline & Material Ramah Lingkungan & $\begin{array}{l}\text { Beitou Public Library memanfaatkan material kayu sebagai material } \\
\text { yang dominan pada bangunan. Kayu merupakan material yang dapat } \\
\text { ditanam dan digunakan kembali sehingga termasuk dalam salah satu } \\
\text { kategori material ramah lingkungan menurut Karyono (2014) yaitu } \\
\text { material terbarukan (Renewable Material) }\end{array}$ \\
\hline
\end{tabular}

Sumber: Hasil Analisis, 2019

\section{KESIMPULAN}

Berdasarkan analisis diatas dapat disimpulkan bahwa bangunan Beitou public library ini menerapkan beberapa prinsip arsitektur hijau berdasarkan teori arsitketur yang digunakan meliputi penempatan lokasi dan tapak, pengolahan tapak, penghematan energi pada bangunan, penggunaan energi terbarukan, serta penggunaan material ramah lingkungan. Dibawah ini merupakan poin-poin penjelasan mengenai penerapan arsitektur hijau pada Beitou public library, sebagai berikut :

1. Penempatan lokasi dan tapak

Beitou Public Library terletak pada kontur tanah yang cukup rendah sehingga berpotensi terjadi banjir akan tetapi dengan memilki area hijau yang cukup luas sehingga terdapat banyak area resapan air yang dapat membantu mengurangi potensi terjadinya banjir.

2. Pengolahan tapak 
Perpustakaan ini tidak terlalu banyak mengubah atau mengolah lahan sehingga kualitas lahan tetap terjaga.

\section{Penghematan Energi}

Bangunan perpustakaan ini mengarah ke utara sehingga terhindar dari panas sinar matahari secara langsung terhadap bangunan dan memanfaatkan sinar matahari tidak langsung untuk pencahayaan pada ruang serta memanfaatkan sirkulasi udara silang dengan menggunakan bukaan di kedua sisi bangunan.

4. Penggunaan Energi Terbarukan

Beitou Public Library memanfaatkan energi solar sel (photovoltaic) yang mana teknologi ini menghasilkan energi listrik yang dapat membantu bangunan untuk mengurangi penggunaan listrik berbayar dan juga membantu mengurangi pemanasan global juga mengemisi $\mathrm{CO} 2$.

5. Penggunaan Material Ramah Lingkungan

Beitou Public Library memanfaatkan material kayu sebagai material yang dominan pada bangunan. Kayu merupakan material yang dapat ditanam dan digunakan kembali sehingga termasuk dalam salah satu kategori material ramah lingkungan menurut Karyono (2014) yaitu material terbarukan (Renewable Material).

\section{DAFTAR REFERENSI}

Afifah, R., Hakim, L., \& Anisa. (2018). Penerapan Konsep Arsitektur Hijau pada Bangunan Pusat Penelitian dan Pengembangan Tanaman Herbal di Lembang Bandung. volume $2 \mathrm{n}$.

Anisa. (2010). Aplikasi Green Architecture Pada Rumah Gedong. VI(2), 158-168.

Karyono, tri harso. (2014). Pengantar Pemahaman Arsitektur Hijau di Indonesia. Radjagrafindo perkasa.

Sudarwani, M. (2012). Penerapan Green Architecture dan Green Building Sebagai Upaya Pencapaian Sustainable Architecture.

Brenda, \& Vale, R. (1991). Green Architecture : Design for A Sustainable Future. thames \& hudson.

Saleh, A. R. (2016). Peranan Teknologi Informasi dalam Meningkatkan Kegemaran Membaca dan Menulis Masyarakat. May, 42-49.

Bambang. (2012). The Utilization Of Library As A Leaning Resource Center To Enhance The Quality Of Learning . 199-213.

Sassi, P. (2006). Strategies for Sustainable Architecture. Taylor \& Francis.

Kurniawati, A. D., \& Irhandayaningsih, A. (2018). Pemaknaan Perpustakaan Di Kalangan Pedagang Di Kawasan Malioboro.

Josephine Ershanti, Winarso Yosafat, W., \& Samsudi. (2019). Aplikasi Pendekatan Arsitektur Hijau Pada Bangunan Perpustakaan Anak Di Kabupaten Sukoharjo Dengan Aspek Efisiensi Dan Konservasi Energi. 193-202. 